\title{
Physiological activation of human neutrophils down-regulates CD53 cell surface antigen
}

\author{
Faustino Mollinedo, ${ }^{*}$ Belén Martín-Martín, ${ }^{*}$ Consuelo Gajate, ${ }^{*}$ and Pedro A. Lazo ${ }^{\dagger}$ \\ * Laboratory of Signal Transduction and Leukocyte Biology, Instituto de Biología y Genética M ol ecular, Facultad de \\ Medicina, Consejo Superior de Investigaciones Científicas-Universidad de Valladolid, Spain, and UU nidad de Genética y \\ Medicina Molecular (Consejo Superior de Investigaciones Científicas), Centro Nacional de Biología F undamental, \\ Instituto de Salud Carlos III, Majadahonda, Spain
}

\begin{abstract}
Tetraspanin transmembrane proteins have a metastasis suppressor effect by acting as cell motility brakes in tumor cells. CD 53 is a panleukocyte antigen that belongs to the tetra-span superfamily. H uman neutrophils express high levels of CD 53. We tested the hypothesis that this antigen level changes when cells are activated. Treatment of human neutrophils with their physiological activators, tumor necrosis factor $\alpha$ or platelet-activating factor, resulted in down-regulation of this antigen from the cell surface, as assessed by immunofluorescence flow cytometry. Similar responses were observed when neutrophils were stimulated with chemotactic $\mathrm{N}$-formyl-methionyl-leucyl-phenylalanine, phorbol ester, or the calcium ionophore ionomycin. The CD53 antigen down-regulation upon neutrophil stimulation was further confirmed by immunoblotting analysis and was not correlated with a change in the level of CD53 transcripts. This CD 53 antigen down-regulation paralleled that of CD 43 and CD44 antigens in these cells, despite their different protein structure. The down-regulation of the three antigens CD 53, CD 43, and CD 44 could be inhibited by phenylmethylsulfonyl fluoride, suggesting that CD53 antigen down-regulation is the result of the activation of a proteolytic mechanism. Down-regulation of CD53 antigen level, as a result of cellular stimulation, might play a role in the different aspects of neutrophil biology, by modulating its interactions on the cell surface. J. Leukoc. Biol. 63: 699-706; 1998.
\end{abstract}

Key Words: cell surface molecule - human, tetraspanin antigens . tumor necrosis factor - platelet-activating factor - phorbol ester . $\mathrm{CD} 44 \cdot \mathrm{CD} 43$

\section{INTRODUCTION}

The tetraspanin family is a novel group of membrane proteins that has been implicated in several important biological processes, but their physiological role in cell biology is not yet known [1-3]. Therefore, this protein family is still defined by the common structural features of its members [3]. They have four transmembrane domains, their amino and carboxy ends are facing the cytoplasm, and have two, small and large, extracellu-
Iar loops. The large extracellular loop accounts for most of the differences found among the distinct members of this group, it is glycosylated in most cases and appears to be implicated in binding to an unknown ligand [3]. Tetra-span transmembrane proteins include several tumor markers as well as positive and negative regulators of cell proliferation and of cell motility. A mong the tetra-span transmembrane proteins $[2,3]$ are CD 37, a B cell marker; CD53/0X 44, which modulates growth properties; CD81/TAPA1, which has antiproliferative properties; CD63/ME 491, a melanoma antigen; CD9/MRP1, which affects cell motility; and CD82//A4/C33/KAI1, which inhibits syncitium formation in HTLV-I-infected cells [4].

Some tetra-span transmembrane proteins, such as CD9/ MRP1 and CD 82/KAI1, have been shown to exert a metastasis suppressor phenotype in pancreatic and prostate cancer $[5,6]$. This phenotype appears to be the result of a braking effect on cell motility, thus low levels will facilitate cell motility and result in an increased capacity to form metastasis. In five types of cancer, melanoma [7], non small-cell lung cancer [8,9], breast [10], prostate [11], and pancreas [12], the level of tetra-span antigens supports the correlation of low level expression with poor prognosis.

Several tetraspanin antigens are known to promote cellular adhesion. This has been demonstrated for CD81 [13], CD 9 [14], and CD53 [15, 16]. These three antigens are also known to coprecipitate together, suggesting they are forming a complex on the cell membrane which is physically associated with integrins on the cell surface and modulates their biological functions [17-19].

We reasoned that the braking action is a phenotypic manifestation of the biological effect of tetra-span proteins, which can modulate integrin function [17-19]. In normal cells where migration plays an important role, such as neutrophil response to infection, which requires mobilization of cells to the site of

\footnotetext{
Abbreviations: TM4SF, transmembrane-4-superfamily; PAF, plateletactivating factor; PKC, protein kinase C; DIFP, diisopropyl fluorophosphate; TNF- $\alpha$, tumor necrosis factor $\alpha$; fMLP, N-formyl-methionyl-leucyl-phenylalanine; PMA, phorbol 12-myristate13-acetate; FITC, fluorescein isothiocyanate; HEPES, N-2-hydroxyethylpiperazine- $\mathrm{N}$-2-ethanesulfonic acid; SDS, sodium dodecyl sulfate.

Correspondence: Pedro A. Lazo, CNBF, Instituto de Salud Carlos III, 28220 Majadahonda, Madrid, Spain. E-mail: plazozbi@isciii.es

Received July 18, 1997; revised January 27, 1998; accepted January 29, 1998
} 
local infection, these proteins could modulate their levels depending on the activation state. Thus, it could be envisaged that when cells are stimulated with chemotactic agents there should be a reduction in the cell surface level of tetraspanin proteins. We tested this hypothesis using human neutrophils and determining the changes of CD53 antigen levels in response to different types of stimuli.

The human CD53 antigen [3] is a tetraspanin panleukocyte antigen that is detected in cells of lymphoid and myeloid lineages, including B and T lymphocytes, macrophages, neutrophils, and natural killer (NK) cells, but not in erythroid cells [1, 2]. CD53 has been associated with immunocompetence and positive selection in the thymus $[20,21] . C D 53$ is not present in cell lineages from other origins, differing in this regard from other tetraspanin proteins that are also present in cells with an epithelial origin, including several types of carcinoma [3]. The widespread distribution of CD53 in all leukocytes suggests that it might have a similar biological role in all of them. CD53 cross-linking, in rat macrophages, activates a cellular response that is mediated by protein kinase $\mathrm{C}$ (PKC) and releases nitric oxide as a consequence of inducing expression of nitric oxide synthase [22].

Neutrophil biology requires the participation of several types of membrane proteins to carry out different functions, like attachment and detachment to endothelium and target cells as well as cellular migration to places of local infection. These processes require selective and regulated neutrophil-endothelium and cell-cell interactions, which are mediated by a large array of membrane proteins, as well as regulation of cell motility [23-25]. Neutrophil activation in response to different signals, such as chemotactic peptides or cytokines, involves the modulation of the cell surface expression of several proteins, some are down-regulated and others are up-regulated. This change in the levels of cell surface proteins results in neutrophil detachment, migration, rolling, extravasation, and accumulation at the site of injury [25-29]. In this context, proteolytic modulation of membrane proteins is becoming an important regulatory mechanism in cell biology. This proteolytic downregulation has been shown on an increasing number of proteins, including some cytokine receptors such as tumor necrosis factor $\alpha($ TNF $-\alpha)$ receptor and interleukin-6 (IL-6) receptor [30], Fas ligand [31], adhesion molecules such as L-selectin [32, 33], ICAM-3 [34], CD43, and CD44 [35]. Specific proteases are present on the cell surface to specifically activate the thrombin and plasminogen systems [36, 37]. Cell surface proteolytic activity has also been implicated in human neutrophil activation [38, 39].

We have found that the cell surface expression of the CD53 antigen is down-regulated on neutrophil activation. This antigen down-regulation is triggered by several physiological neutrophil activating agents, and correlates well with the previously reported proteolytic down-regulation of other glycoproteins, CD 43 and CD 44 [35].

\section{MATERIALS AND METHODS}

\section{Chemicals and reagents}

Cell culture reagents were from Flow Laboratories (Irvine, CA). Phorbol 12-myristate 13-acetate (PMA), fMLP, cytochalasin B, phenylmethylsulfonyl fluoride (PMSF), diisopropyl fluorophosphate (DIFP), Bdellin, and antitrypsin inhibitor were from Sigma (St. Louis, M O). Ficoll-H ypaque was from Pharmacia (U ppsala, Sweden). I onomycin was from Cal biochem (San Diego, CA ). A crylamide, bisacrylamide, ammonium persulfate, TEMED, and prestained molecular weight markers were from Bio-R ad (Hercules, CA). All other chemicals were from M erck (Darmstadt, Germany) or Sigma.

\section{Monoclonal antibodies}

mAb were used as hybridoma culture supernatants. MEM53 (anti-human CD53) was a gift of Dr. Vaclav Horejsi (Czech Academy of Sciences, Prague, Czech Republic) and was also obtained from Serotec (Oxford, UK). The mAb Bear-1, recognizing CD11b, was kindly provided by Dr. J. E. De Vries (Unicet, Lyon, France) [40]. Anti-CD 43 (mA b TP1/36.1), anti-CD 44 (mA b H P2/9), and mA b W6/32 (specific for a monomorphic determinant on HLA-A,B molecules) $[35,41]$ were kindly provided by Dr. F. Sánchez-Madrid (Hospital de La Princesa, Madrid, Spain). P3X 63 myeloma culture supernatant was used as negative control.

\section{Neutrophil isolation}

Human neutrophils were obtained from fresh peripheral blood by dextran sedimentation and centrifugation on Ficoll-Hypaque followed by hypotonic Iysis of residual erythrocytes as previously described [42]. The final cell preparation contained more than $98 \%$ neutrophils, as assessed by GiemsaWright staining.

\section{Immunofluorescence flow cytometry}

Immunofluorescence flow cytometry analysis was performed in a FACStar-Plus flow cytometer (Becton-Dickinson, San J ose, CA) as previously described [43]. Cells were incubated at $4^{\circ} \mathrm{C}$ with the corresponding $\mathrm{mA} b$ followed by washing and labeling with a fluorescein isothiocyanate (FITC)-labeled-goat anti-mouse IgG antibody (DAK O, Glostrup, Denmark). Linear and logarithmic immunofluorescence values were obtained in each experiment and the fluorescence produced by the myeloma P $3 \times 63$ supernatant was considered as background. Specific linear fluorescence was obtained by subtracting the control fluorescence in which the mA b was substituted by the myeloma P $3 \times 63$.

\section{Neutrophil activation}

Cells were resuspended at $3 \times 10^{6}$ neutrophils/mL in N-2-hydroxyethylpiperazine- $\mathrm{N}^{\prime}$-2-ethanesulfonic acid (HEPES)/glucose buffer (150 mM NaCl, $5 \mathrm{mM}$ $\mathrm{KCl}, 10 \mathrm{mM}$ HEPES, $1.2 \mathrm{mM} \mathrm{MgCl} 2,1.3 \mathrm{mM} \mathrm{CaCl}_{2}, 5.5 \mathrm{mM}$ glucose, $\mathrm{pH} 7.5$ ) and incubated in the absence or presence of distinct stimuli at $37^{\circ} \mathrm{C}$ for the times indicated in the respective legends. Subsequently, cells were sedimented by centrifugation at $300 \mathrm{~g}$ for $10 \mathrm{~min}$. Supernatants were saved and lyophilized to determine release of proteins, and the pelleted cells were saved to determine the content of different cell surface antigens by flow cytometry. Also, sedimented cells were used to obtain membranes for immunoblot analysis. Cells were disrupted by freeze-thaw, and membranes were sedimented by centrifugation at $100,000 \mathrm{~g}$ for $90 \mathrm{~min}$ at $4^{\circ} \mathrm{C}$ in a Beckman TLA rotor [44]. Membrane pellets were resuspended in $50 \mathrm{mM}$ Tris- $\mathrm{HCl}, \mathrm{pH} 7.5$, containing 2 mM PMSF and stored at $-20^{\circ} \mathrm{C}$ until use.

\section{Immunoblot analysis}

Total membrane proteins $(40 \mu \mathrm{g})$ from resting and activated human neutrophils were separated through sodium dodecyl sulfate (SDS), 10 or $15 \%$ polyacrylamide gel electrophoresis under reducing conditions, in the presence of 2-mercaptoethanol, transferred to nitrocellulose filters, and subjected to immunological detection as previously described [45]. A fter electroblotting and blocking for $1-2 \mathrm{~h}$ in $2 \%(\mathrm{w} / \mathrm{v})$ powdered defatted milk in TBS $(50 \mathrm{mM}$ Tris- $\mathrm{HCl}, \mathrm{pH} 8.0,150 \mathrm{mM} \mathrm{NaCl}$ ), the nitrocellulose filters were incubated overnight with the specific anti-CD53 mA b at a dilution of $1 / 400$ in TBS buffer containing $0.05 \%(\mathrm{v} / \mathrm{v})$ Tween 20. Signal was developed using the biotinstreptavidin-horseradish peroxidase system and detected with the ECL kit (A mersham, Little Chalfont, UK) according to the manufacturer's instructions. 


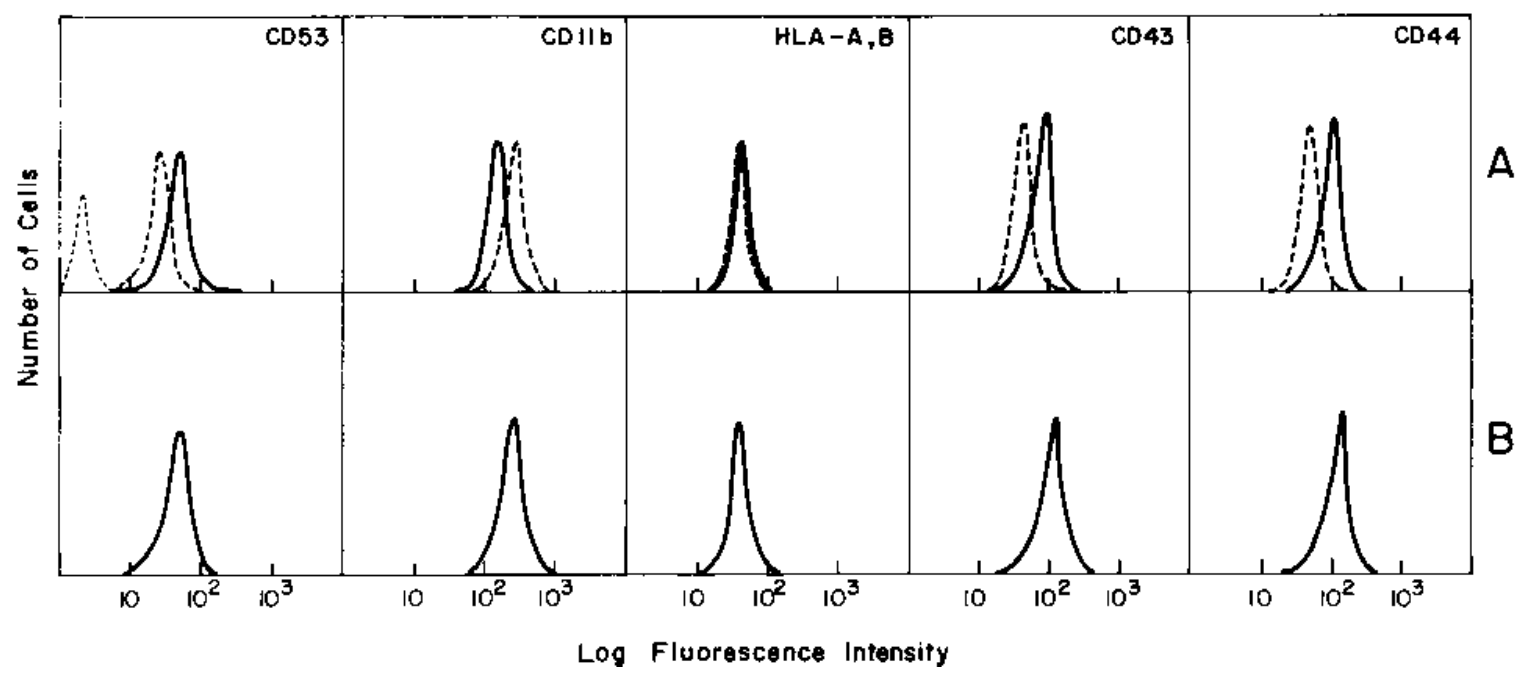

Fig. 1. Effect of TNF- $\alpha$ on the cell surface antigen expression in human neutrophils. (A) Neutrophils were incubated for 15 min at $37^{\circ} \mathrm{C}$ in the absence of any stimulus (solid lines) or in the presence of $500 \mathrm{U} / \mathrm{mL} \mathrm{TNF}$ - $\alpha$ (dashed lines). (B) Neutrophils were incubated for $15 \mathrm{~min}$ with $500 \mathrm{U} / \mathrm{mL}$ TNF - $\alpha$ in the presence of $2 \mathrm{mM}$ PMSF (solid lines). Cells were stained for CD53, CD11b, HLA-A,B, CD43, and CD 44 antigens and analyzed by immunofluorescence flow cytometry as described in Materials and Methods. Staining with negative control antibody P3X 63 is also shown (A, dotted line). One representative experiment out of four is shown.

\section{Northern blot analysis}

RNA was extracted from the cells according to standard protocols using the acid guanidinium-phenol-chloroform extraction method. Ten micrograms of total RNA were electrophoresed on $0.9 \%$ agarose-formaldehyde gels and then transferred to $\mathrm{Hybond}-\mathrm{N}$ nylon membranes (A mersham) and hybridized to the appropriate probe following standard protocols [46]. We used the human CDNA clone, ph15CD53, containing the complete CD53 coding region [P. A. Lazo, unpublished results] as a probe for CD53. For internal controls a CDNA probe against glyceraldehyde-3-phosphate dehydrogenase was used.

\section{RESULTS}

Human neutrophils are physiologically activated by the cytokine TNF- $\alpha$ and PAF, a potent phospholipid mediator. Both molecules play important regulatory roles in neutrophil recruitment to sites of injury. We found that CD53 was down-regulated after neutrophil stimulation with $500 \mathrm{U} / \mathrm{mL}$ of TNF $-\alpha$ (Fig. 1). TNF - $\alpha$ is also known to down-regulate sialophorin (CD43) and the hyaluronic acid receptor (CD 44) during neutrophil activation by a proteolytic mechanism that is inhibited by PM SF [35]. We determined these two antigens as down-regulation controls in all experiments. As additional control antigens we used $C D 11 b$, an integrin that is up-regulated in neutrophil activation [44], and HLA-A,B, which is not affected by cell stimulation.
As shown in Figure 1, CD53 antigen, as well as CD43 and $C D 44$, were down-regulated, whereas the cell surface expression of CD11b was up-regulated, and that of HLA-A,B was unaffected. We conclude from these data that CD53 antigen down-regulation is also part of the human neutrophil response to TNF- $\alpha$ (Fig. 1, Table 1). All TNF- $\alpha$-induced downregulation reactions were inhibited by the addition of $2 \mathrm{mM}$ PMSF. The stimulation of human neutrophils with $1 \mu \mathrm{M}$ PAF for 15 min also triggered a reduction in CD53, CD 43, and CD 44 antigen levels, which were partially inhibited by the addition of PMSF (Table 1). It is interesting to note that PMSF did not affect the overexpression of CD11b (Table 1), thus ruling out the possibility that PMSF could block the overall neutrophil activation mechanism.

Neutrophils can be activated by stimulation with $\mathrm{fMLP}$, a short chemotactic peptide that induces changes in the cell surface expression levels of several antigens [47]. fMLP stimulates neutrophils through a PKC-dependent pathway [48, 49]. We have determined the fate of CD53 antigen in human neutrophils that have been stimulated with fM LP (Fig. 2, Table 1). The addition of $1 \mu \mathrm{M} \mathrm{fMLP}$ for 15 min induced a reduction in the cell surface CD53 antigen level on these cells (Fig. 2). This CD53 down-regulation was also observed after $5 \mathrm{~min}$ incubation with FMLP (data not shown). The FMLP-induced

TABLE 1. Effect of Distinct Physiological Stimuli on the Cell-Surface Expression of Several Leukocyte Antigens in H uman Neutrophils

\begin{tabular}{|c|c|c|c|c|c|c|c|}
\hline Cell surface antigen & $37^{\circ} \mathrm{C}$ & TNF $-\alpha$ & TNF- $\alpha+$ PMSF & PAF & $\mathrm{PAF}+\mathrm{PMSF}$ & $f M L P$ & fMLP + PMSF \\
\hline CD53 & (2) & 156 & 41 & 5) & $46 \pm 2(100)$ & $5(41)$ & $3(87)$ \\
\hline $\begin{array}{l}\text { CD43 sialophorin } \\
\text { CD44 hyaluronate }\end{array}$ & $87 \pm 7$ & 5 & (111) & $3(64)$ & (113) & $33 \pm$ & (99) \\
\hline receptor & $96 \pm 8$ & $58 \pm 8$ & 102 & 63 & 97 & $31=$ & (96) \\
\hline CD11b Mac1, Mol & $216 \pm 15(100)$ & $289 \pm 13$ & $301 \pm 21(139)$ & $298 \pm 10$ & $296 \pm 12(137)$ & $396 \pm 27(183)$ & $331 \pm 24(153$ \\
\hline$H L A-A, B$ & $48 \pm 7(100)$ & $43 \pm 2(90)$ & $45 \pm 4(94)$ & $44 \pm 1(92)$ & $46 \pm 4(96)$ & $41 \pm 6(85)$ & $43 \pm 3(90)$ \\
\hline
\end{tabular}

Neutrophils were incubated for $15 \mathrm{~min}$ at $37^{\circ} \mathrm{C}$ either in the absence or in the presence of the following stimuli: $500 \mathrm{U} / \mathrm{mL} \mathrm{TNF}-\alpha, 1 \mu \mathrm{M} \mathrm{PAF}, 1 \mu \mathrm{M} \mathrm{fMLP}$. When indicated, cells were preincubated for $5 \mathrm{~min}$ with $2 \mathrm{mM}$ PMSF. Cells were analyzed by immunofluorescence flow cytometry. Data are expressed as means \pm SD of specific linear fluorescence intensity values of four independent experiments. The values in parentheses indicate the percentage of cell surface antigen expression with respect to that of untreated control cells at $37^{\circ} \mathrm{C}$ with no additions. The fMLP experiments were carried out in the presence of $5 \mu \mathrm{g} / \mathrm{mL}$ cytochalasin B. 
CD53 down-regulation was blocked by addition of PMSF (Fig. 2; Table 1). The fMLP-induced CD53 down-regulation paralleled the responses of CD43 and CD44, used as control antigens for down-regulation (Table 1). In contrast, CD11b was up-regulated, and HLA-A,B was not affected (Table 1).

Signaling mediated by $P K C$, such as stimulation with phorbol esters or $\mathrm{Ca}^{2+}[50]$, can also activate human neutrophils. Therefore, we tested the effects of PMA and the $\mathrm{Ca}^{2+}$ ionophore, ionomycin, on CD53 surface level. Phorbol esters and $\mathrm{Ca}^{2+}$ ionophores are potent activators of neutrophil functions. Shortly after the addition of $100 \mathrm{ng} / \mathrm{mL}$ PMA or $3 \mu \mathrm{M}$ ionomycin to neutrophils there was a decrease in the CD53 antigen cell surface level (Fig. 2, Table 2). The PMA-induced CD53 down-regulation was very rapid, and similar to the fML P-induced down-regulation (Fig. 2). Down-regulation could be detected following PMA treatment as rapidly as 5 min (data not shown). This mechanism appears to be mediated by PKC signaling, as preincubation of neutrophils with either $50 \mu \mathrm{M} \mathrm{H} 7$ or $150 \mathrm{nM}$ staurosporine completely abrogated CD53 downregulation (data not shown). CD53 (F ig. $\mathbf{3 A}$ ) responded to PMA in the same way as CD 43 (Fig. 3C) and CD 44 (Fig. 3D). The use of serine protease inhibitors, such as PMSF, prevented the PMA or ionomycin-induced down-regulation of CD53 cell surface expression (Fig. 2, Table 2), as well as that of CD43 and CD44

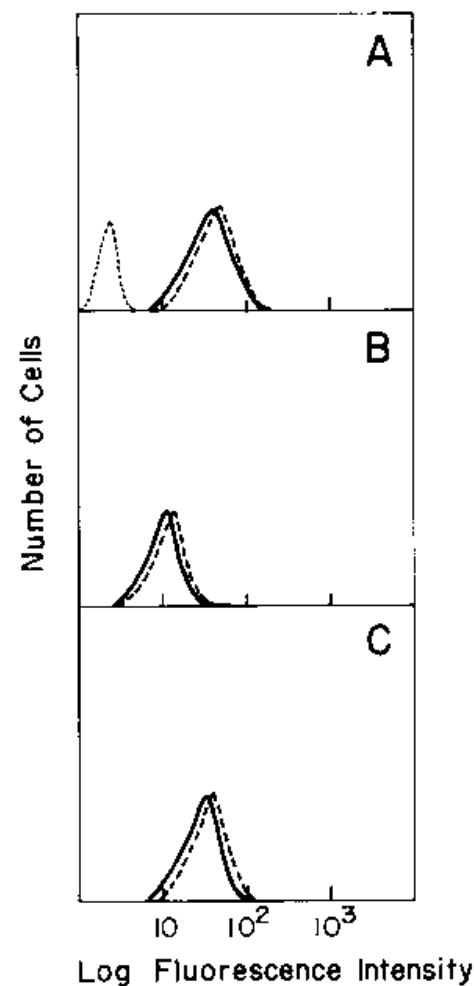

Fig. 2. Down-regulation of $C D 53$ antigen on cell stimulation with $P M A$ or FMLP and its prevention by PMSF in human neutrophils. (A) Neutrophils were incubated for $15 \mathrm{~min}$ at $4^{\circ} \mathrm{C}$ (solid line) or $37^{\circ} \mathrm{C}$ (dashed line) in the absence of any stimulus. (B) Neutrophils were incubated for $15 \mathrm{~min}$ at $37^{\circ} \mathrm{C}$ in the presence of $100 \mathrm{ng} / \mathrm{mL}$ of PMA (solid line) or $1 \mu \mathrm{M} \mathrm{fMLP}$ (dashed line). (C) Neutrophils were incubated as in (B) but in the presence of $2 \mathrm{mM}$ PMSF during the activation process. Cells were stained for CD53 antigen and analyzed by immunofluorescence flow cytometry. Staining with the negative control P3X63 is also shown (A, dotted line). One representative experiment out of five is shown.

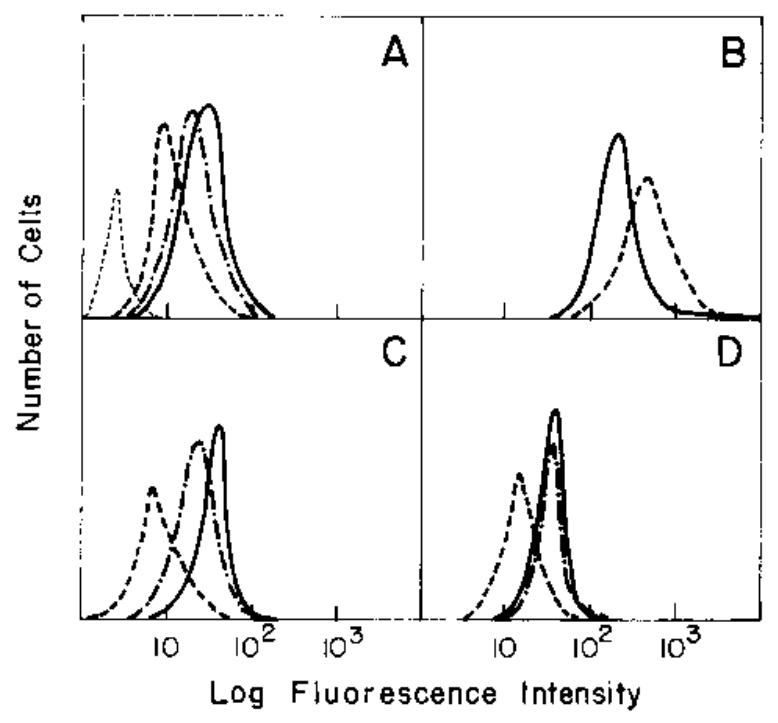

Fig. 3. Effect of PMA on the cell-surface expression of CD53, CD11b, CD43, and CD44 antigens in human neutrophils. Neutrophils were incubated in the absence of any stimulus or in the presence of $100 \mathrm{ng} / \mathrm{mL}$ PMA for $15 \mathrm{~min}$ at $37^{\circ} \mathrm{C}$. R esting (solid line) and stimulated (dashed) cells were stained for CD53 $(A), C D 11 b(B), C D 43(C)$, and CD44 (D) antigens and analyzed by immunofluorescence flow cytometry as described in Materials and Methods. Cells were also incubated with PMA in the presence of 2 mM PMSF (dotted dashed line) and examined for the above antigens. Staining with the negative control P3X 63 is also shown ( $A$, dotted line). One representative experiment out of four is shown.

(Fig. 3, Table 2). The control CD11b up-regulation was also observed in our assays (Fig. 3B), but the increase in this antigen level was smaller in the presence of PMSF (Table 2). In an attempt to further characterize the protease implicated in CD53 down-regulation we used additional protease inhibitors. DIFP, another serine protease inhibitor, prevented CD53 downregulation, whereas $B$ dellin, an inhibitor of metalloproteinases, leupeptin, and anti-trypsin inhibitor did not prevent CD53 down-regulation (data not shown). Based on these observations, we suggest that a signal mediated by PKC can proteolytically down-regulate CD53 antigen.

Time course studies of CD53 down-regulation on PMA or TNF- $\alpha$ treatment showed that CD53 down-regulation was almost complete after $1 \mathrm{~h}$ incubation (Fig. 4).

The loss of CD53 antigen could be due to internalization by endocytosis as a consequence of neutrophil stimulation. Therefore, we performed experiments in the presence of cytochalasin $B$, a microfilament disrupting agent, which has been used as an inhibitor of endocytosis [51]. Cytochalasin B did not prevent down-regulation of CD53 antigen (Table 2). Cytochalasin B has been widely used to enhance neutrophil responses, increasing exocytosis. This is clearly observed in Table 2, where the up-regulation of CD11b is highly increased as a result of the mobilization of internal CD11b pools in intracellular granules [44].

Immunoblotting of CD53 antigen from neutrophil membranes clearly showed a diminished surface expression of this molecule on activated, compared with resting neutrophils (Fig. 5A), in accordance with the immunofluorescence flow cytometry data. The human CD53 antigen can be N-glycosylated and both forms, glycosylated and non-glycosylated, are present on the cellular membrane of different cell types [52]. In human 
TABLE 2. Effect of PMA and ionomycin on the cell surface expression of several leukocyte antigens in human neutrophils and inhibition by PMSF

\begin{tabular}{|c|c|c|c|c|c|c|c|}
\hline Antigen/CD & $4^{\circ} \mathrm{C}$ & $37^{\circ} \mathrm{C}$ & PMA & PMA + PMSF & Ionomycin & $\begin{array}{c}\text { Ionomycin }+ \\
\text { PMSF }\end{array}$ & $\begin{array}{c}\text { Ionomycin + } \\
\text { cytochalasin } \\
\text { B + PMA }\end{array}$ \\
\hline ME M53 CD53 & $45 \pm 5$ & $46 \pm 7(100)$ & $16 \pm 5(34)$ & $33 \pm 9(72)$ & $23 \pm 5(51)$ & $38 \pm 2(83)$ & $19 \pm 22(42)$ \\
\hline Sialophorin CD43 & $91 \pm 8$ & $87 \pm 7(100)$ & $27 \pm 4(31)$ & $80 \pm 9(91)$ & $20 \pm 1(23)$ & $105 \pm 8(120)$ & N.D. \\
\hline H yaluronate receptor CD 44 & $97 \pm 9$ & $96 \pm 8(100)$ & $40 \pm 6(41)$ & $94 \pm 7(97)$ & $21 \pm 3(21)$ & $87 \pm 7(90)$ & N.D. \\
\hline Mac1, Mol CD11b & $181 \pm 11$ & $216 \pm 15(100)$ & $481 \pm 25(222)$ & $320 \pm 41(148)$ & $484 \pm 31(224)$ & $301 \pm 48(139)$ & $545 \pm 35(301)$ \\
\hline$H L A-A, B$ & $46 \pm 3$ & $48 \pm 7(100)$ & $38 \pm 6(83)$ & $42 \pm 6(91)$ & $39 \pm 5(81)$ & $41 \pm 4(90)$ & $47 \pm 4(98)$ \\
\hline
\end{tabular}

Neutrophils were held at $4^{\circ} \mathrm{C}$ or treated for $15 \mathrm{~min}$ at $37^{\circ} \mathrm{C}$ either in the absence of any stimulus or in the presence of the following stimuli: $100 \mathrm{ng} / \mathrm{mL} P M A, 3 \mu \mathrm{M}$ ionomycin. When indicated, cells were preincubated for $5 \mathrm{~min}$ with $2 \mathrm{mM} \mathrm{PMSF}$ or $5 \mu \mathrm{g} / \mathrm{mL}$ cytochalasin B. Cells were analyzed by immunofluorescence flow cytometry. Data are expressed as means \pm SD of specific linear fluorescence intensity values. M ean values were obtained from four independent cells experiments. In parentheses are the values represented as percentage of the cell surface antigen expression with respect to that found in untreated control cells determined at $37^{\circ} \mathrm{C}$. N.D., not determined.

neutrophils, we detected by immunoblotting two bands of approximately 35 and $21 \mathrm{kDa}$, corresponding to both forms of CD53. Treatment with PMA resulted in the loss of both CD53 forms and the addition of PMSF inhibited this proteolytic down-regulation. These observations confirmed that glycosylated and non-glycosylated CD53 were down-regulated, likely by proteolysis. As control antigen in these experiments we used CD43, which is also lost after stimulation with PMA, and this response is also inhibited by addition of PMSF (Fig. 5A). The proteolytic attack could have two effects, either solubilizing the CD53 antigen or simply destroying the only accessible loop to the antibody and thus losing immunoreactivity. We were unable to detect soluble CD53 antigen (data not shown). These results suggest that the proteolytic attack could affect the extracellular loop where the antigenic epitope is located.

We also determined whether, as a result of PMA stimulation, there were changes in the level of mR NA coding for CD53 (Fig. $5 B)$. The drop in CD53 cell surface expression after neutrophil activation suggested that the synthesis of new antigen might also be turned off as a result of down-regulation. Total RNA from neutrophils prepared at different time points before and after different types of stimulation were analyzed by Northern blot. The blot was hybridized to a human CD53 CDNA probe. As shown in Figure $5 B$, there were no changes in the CD53 mRNA level despite the reduction in membrane antigen levels.

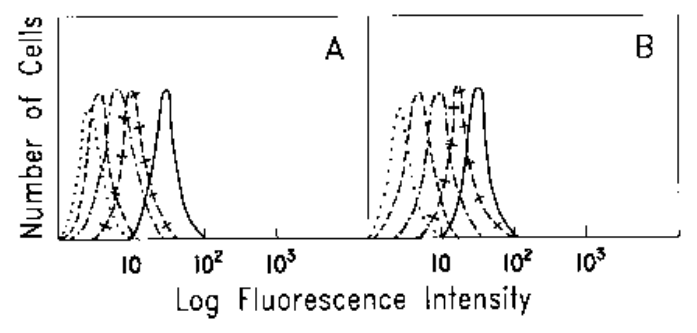

Fig. 4. Time-course assay of the effect of PMA and TNF- $\alpha$ on CD53 antigen surface level in human neutrophils. Neutrophils were incubated at $37^{\circ} \mathrm{C}$ in the absence (solid line) or in the presence of $100 \mathrm{ng} / \mathrm{mL}$ PMA (A) or $500 \mathrm{U} / \mathrm{mL}(B)$ for $15 \mathrm{~min}$ (dashed line with plus signs), $30 \mathrm{~min}$ (dotted dashed line), and 60 min (dashed line). Then cells were stained for CD53 antigen and analyzed by immunofluorescence flow cytometry. Staining with the negative control P $3 \times 63$ is also shown (dotted line). One representative experiment out of three is shown.

\section{DISCUSSION}

Tetraspanin transmembrane proteins in tumor cells appear to function as metastasis suppressors, by acting as brakes of cell motility $[5,6]$. Thus low levels of these proteins have been
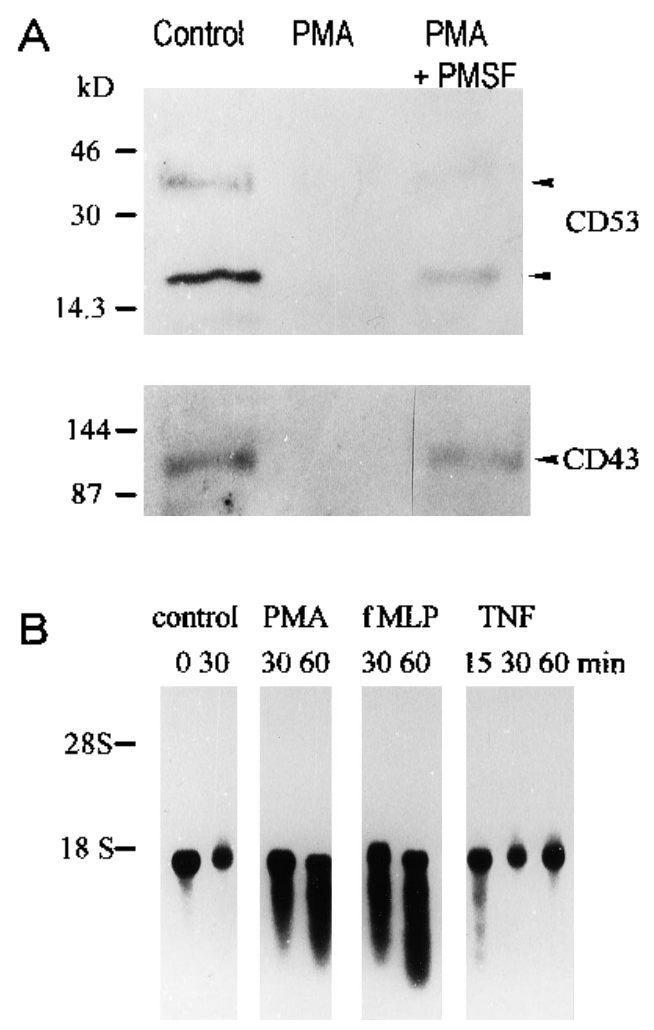

Fig. 5. Western blot and Northern blot analysis of CD53 in resting and activated human neutrophils. (A) Western blot analysis of membrane fractions from resting and activated human neutrophils. Blots contained $40 \mu \mathrm{g}$ of membrane proteins from control untreated neutrophils, neutrophils treated with PMA for $30 \mathrm{~min}$, and neutrophils treated for $30 \mathrm{~min}$ with PMA in the presence of PMSF. Blots were analyzed with anti-CD53 mAb (top panel) or with anti CD $43 \mathrm{~mA} \mathrm{~b}$ (bottom panel). (B) Northern blot analysis of mR NA levels of CD53 in human neutrophils after stimulation with PMA, fMLP, or TNF- $\alpha$ for different incubation times. The Northern blot was hybridized to a human complete cDNA probe for CD53. Basal control levels in untreated neutrophils are also shown. A utoradiograph was developed after 24-h exposure. 
correlated with an increased metastatic potential, and thereby poor prognosis [7-11].

In human neutrophils, as a result of activation, there is an increase in cell motility in order to migrate to the site of injury. Therefore we postulated that if the CD53 panleukocyte antigen was having an inhibitory effect on cell motility in this cell type, it should reduce its surface level after physiological stimulation.

We herein report a significant down-regulation in the levels of CD53 antigen on the cell surface during human neutrophil activation by different activators, such as TNF- $\alpha$, PAF, and $f M L P$, signaling through a receptor-mediated pathway, and PMA and ionomycin, signaling via PKC, through a non-receptor route. The regulatory effects of TNF- $\alpha$ and PAF on CD53 cell expression were weaker than those exerted by PMA or ionomycin. However, on 1-h incubation with either PMA or TNF- $\alpha$, CD53 surface antigen expression was almost completely reduced (Fig. 4). The differences in the CD53 cell surface levels between resting and TNF- $\alpha$-activated neutrophils are similar to those detected between cells with low and high metastatic potential [8-12]. This change in the cell surface antigen level occurred rapidly and and was already detectable after $5 \mathrm{~min}$ stimulation. This rapid response is not accompanied by changes at the mRNA level. The mechanism of this change in CD53 levels is not the result of internalization by endocytosis, as shown by the lack of effect of cytochalasin $B$. The fact that the protease inhibitor PMSF blocks the down-regulation of CD53, but not the up-regulation of the cell surface expression of CD11b induced by TNF - $\alpha$ or PAF may indicate that activation of a specific protease is the mechanism involved in the modulation of CD53. Furthermore, DIF P, another serine protease inhibitor, al so prevents CD53 down-regulation. These data agree with a previous report showing that PMSF prevented the CD43 and CD44 proteolytic down-regulation with no effect on CD11b up-regulation when neutrophils were activated with TNF- $\alpha$ [35]. There is evidence showing that several protease inhibitors can affect different neutrophil functions [38, 39], which is consistent with our observation that in the presence of PMSF the up-regulation of CD11b was smaller when triggered by non-membrane receptor stimuli (Table 2). Thus, protease activation could mediate several aspects of neutrophil biology.

The CD53 down-regulation herein reported was similar to that of CD43 and CD44 [35], and was equally inhibited by PMSF in the three antigens, which suggests that proteolysis is a physiological regulator of neutrophil membrane-associated functions. There is no apparent homology among the three downregulated antigens herein studied, CD53, CD43, and CD 44 . Thus, either there is a family of proteases, one for each target, or there is a protease that recognizes a three-dimensional structure common to apparently unrelated proteins. This putative protease must already be present in an inactive state in the resting cell, because its activation takes place immediately after cell stimulation. The presence of serine protease activity on cell membranes has long been known, like in the case of plasminogen activator [37], and in the activation of human neutrophils [38, 39].

In many cases, the consequence of a protease action is the release of a soluble form of a growth factor, as is the case for
IL-6, TNF- $\alpha$, and FasL. In others, there is no solubilization, just a loss of antigenic reactivity, as is the case with CD43 and CD44 [35]. This latter process is likely to be occurring in the case of $C D 53$, as its very hydrophobic nature with four transmembrane domains makes very unlikely that a proteolytic cleavage could solubilize the protein, particularly when this proteolytic attack appears to occur in the loop of the protein containing the epitope [53]. This is consistent with the lack of detection of CD53 antigen in soluble form upon cell activation, and with the reduction of the antigen level that remains detectable by Western blot on cellular membranes.

Because CD53 antigen is present on the surface of human neutrophils, which have specific interactions in different cellular environments, its cell surface expression modulation might be a mechanism that will allow binding to alternative molecules. In this context, it could be envisaged that neutrophils can detach as a consequence of CD53 down-regulation, and migrate toward a different location, where the cells could bind to a, perhaps, distinct ligand molecule. This issue will only be settled when the specific ligands for CD53 and other tetra-span transmembrane proteins are identified. This is important for two major reasons. First, several tetra-span proteins have been identified as tumor antigens, and their levels have been correlated with tumor prognosis in several types of cancer [7-12]. Second, several tetraspanin antigens are known to be implicated in adhesion processes, such as CD9 [14], CD81 [13], and CD53 [15], and these three antigens interact with integrins and are modulators of integrin functions [54].

The observations reported in this study further call attention to the biological importance of selective proteolytic cleavage in regulation of cell function. The characterization of the specific proteases involved, as well as the identification of specific inhibitors, could open up a field of great biological and pharmacological relevance in the control of specific pathologies. CD53 physiological function remains to be elucidated, but this antigen is a membrane protein that has been implicated in signal transduction [21, 55-57]. The proteolytic downregulation of $\mathrm{CD} 53$, a prototype tetraspanin transmembrane protein, parallels that of other antigens that are also downregulated in neutrophil activation, suggesting that tetraspanin proteins are a component of the neutrophil cellular interactions needed for some unknown aspects of their biology and, by analogy to other neutrophil adhesion proteins, their alteration might have clinical consequences, like recurrent infections. In this regard we have recently reported a family with recurrent infectious diseases that has as the only identified alteration a deficiency of CD53 antigen [58].

\section{ACKNOWLEDGMENTS}

This work was supported by grants from Dirección General de Ciencia y Tecnol ogía, PB 95/0713 (to F. M.), Comisión Interministerial de Ciencia y Tecnología, SAF94/0059 (to P. A. L.), and Fondo de Investigación Sanitaria, FIS95/0413 and FIS 98/0313 (to P. A. L.) and FIS96/1434 (to F. M.). 


\section{REFERENCES}

1. H orejsi, V., VIcek, C. (1991) Novel structurally distinct family of leucocyte surface glycoproteins including CD9, CD37, CD53 and CD63. FEBS Lett. 288, 1-4.

2. Wright, M. D., Tomlinson, M. G. (1994) The ins and outs of the transmembrane 4 superfamily. Immunol Today 15, 588-594.

3. Maecker, H. T., Todd, S. C., Levy, S. (1997) The tetraspanin superfamily: molecular facilitators. FASE B J. 11, 428-442.

4. Imai, T., Fukudome, K., Tagaki, S., Nagira, S., Furuse, M., Fukuhara, N., Nishimura, M., H inuma, Y., Yoshie, 0. (1992) C33 antigen recognized by monoclonal antibodies inhibitory to human T-cell leukemia virus type 1 induced syncytium formation is a member of a new family of transmembrane protein including CD9, CD37, CD53 and CD63. J. Immunol. 149, $2879-2886$.

5. Marx, J. (1995) New clue to prostate cancer spread. Science 268, 799-800.

6. Coffey, D. S. (1996) Prostate cancer metastasis: talking the walk. Nature Med. 2, 1305-1306.

7. Hotta, H., R oss, A. H., Huebner, K., I sobe, M., Wendeborn, S., Chao, M. V., Ricciardi, R. P., Tsujimoto, Y., Croce, C. M., Koprowski, H. (1988) Molecular cloning and characterization of an antigen associated with early stages of melanoma tumor progression. Cancer Res. 48, 2955-2962.

8. Higashiyama, M., Taki, T., leki, Y., Adachi, M., Huang, C., K oh, T., Kodama, K., Doi, O., Miyake, M. (1995) R educed motility related protein-1 (MRP1/CD9) gene expression as a factor of poor prognosis in non-small cell lung cancer. Cancer Res. 55, 6040-6044.

9. Adachi, M., Taki, T., Ieki, Y., Huang, C., Higashiyama, M., Miyake, M. (1996) Correlation of KAII/CD82 gene expression with good prognosis in patients with non-small cell lung cancer. Cancer Res. 56, 1751-1755.

10. Miyake, M., Nakano, K., Ieki, Y., A dachi, M., H uang, C., Itoi, S., Koh, T., Taki, T. (1995) Motility related protein 1(M R P1/CD9) expression: inverse correlation with metastases in breast cancer. Cancer Res. 55, 4127-4131.

11. Dong, J., Lamb, P. W., R inker-Schaeffer, C. W., Vukanovic, J., Ichikawa, T., I saacs, J. T., Barrett, J. C. (1995) KAI1, a metastasis suppressor gene for prostate cancer on human chromosome 11p11.2. Science 268, 884-886.

12. Guo, X., Friess, H., Graber, H. U., Kashigawi, M., Zimmerman, A., Kore, M. (1996) KAII expression is up-regulated in early pancreatic cancer and decreased in the presence of metastases. Cancer Res. 56, 4876-4880.

13. Takahashi, S., Doss, C., Levy, S., Levy, R. (1990) TAPA 1, the target of an antiproliferative antibody, is associated on the cell surface with the Leu-13 antigen. I. Immunol. 145, 2207-2213.

14. Masellis-Smith, A., J ensen, G. S., Seehafer, J. G., Slupsky, J. R., Shaw, A. R. E. (1990) Anti-CD 9 monoclonal antibodies induce homotypic adhesion of pre B cell lines by a novel mechanism. J. Immunol. 144, 1607-1613.

15. Lazo, P. A., Cuevas, L., Gutierrez del A rroyo, A., Orue, E. (1997) Ligation of CD53/0X 44, a tetraspan antigen, induces homotypic adhesion mediated by specific cell-cell interactions. Cell. Immunol. 178, 132-140.

16. Cao, L., Yoshino, T., Kawasaki, N., Sakuma, I., Takahashi, K., A kagi, T. (1997) Anti-CD53 monoclonal antibody induced LFA-1/ICAM-1-dependent and -independent lymphocyte homotypic adhesion. Immunobiol. 197, 70-81.

17. Berditchevski, F., Zutter, M. M., Hemler, M. E. (1996) Characterization of novel complexes on the cell surface between integrins and proteins with 4 transmembrane domains (TM 4 proteins). Mol. Biol. Cell 7, 193-207.

18. Berditchevski, F., Tolias, K. F., Wong, K., Carpenter, C. L., Hemler, M. E. (1997) A novel link between integrins, transmembrane-4-superfamily proteins (CD63 and CD81), and phosphatidylinositol 4-kinase. J. Biol. Chem. 272, 2595-2598.

19. Rubinstein, E., La Naour, F., Lagaudriere-Gesbert, C., Billard, M., Conjeaud, H., Boucheix, C. (1996) CD9, CD63, CD81, and CD82 are components of a surface tetraspan network connected to HLA-DR and VLA integrins. Eur. J. Immunol. 26, 2657-2665.

20. Paterson, D. J., Williams, A. F. (1987) An intermediate cell in thymocyte differentiation that expresses CD 8 but not CD 4 antigen. J. Exp. Med. 166, 1603-1609.

21. Mitnacht, R., Tacke, M. (1995) Expression of cell interaction molecules by immature rat thymocytes during passage through the $\mathrm{CD} 4{ }^{+} \mathrm{CD} 8^{+}$compartment: develomental regulation and induction of $T$ cell receptor engagement of CD2, CD5, CD28, CD11a, CD44, and CD53. Eur. J. Immunol. 25, 328-332.

22. Boscá, L., Lazo, P. A. (1994) Induction of nitric oxide release by MRC 0X-44 (anti-CD53) through a protein kinase C-dependent pathway in rat macrophages. J. Exp. Med. 179, 1119-1126.

23. Madara, J. L. (1994) Migration of neutrophils through epithelial monolayers. Trends Cell Biol. 4, 4-7.

24. Bokoch, G. M. (1995) Chemoattractant signaling and leukocyte activation. Blood 86, 1649-1660.
25. Ley, K. L., Tedder, T. F. (1995) Leukocyte interactions with vascular endothelium: new insights into selectin-mediated attachment and rolling. J. Immunol. 155, 525-528.

26. Kansas, G. S. (1996) Selectins and their ligands: current concepts and controversies. Blood 88, 3259-3287.

27. Bevilacqua, M. P. (1993) Endothelial-leukocyte adhesion molecules. Annu. Rev. Immunol. 11, 767-804.

28. Collins, T. L., Kassner, P. D., Bierer, B. E., Bukaroff, S. J. (1994) A dhesion receptors in lymphocyte activation. Curr. Op. Immunol. 6, 385-393.

29. Buthcher, E. C., Picker, L. J. (1996) Lymphocyte homing and homeostasis. Science 272, 60-66.

30. Mullberg, J., Durie, F. H., Otten-Evans, C., A Iderson, M. R., R ose-J ohn, S., Cosman, D., Black, R. A., Mohler, K. M. (1995) A metalloprotease inhibitor blocks shedding of the IL-6 receptor and the p60 TNF receptor. J . Immunol. 155, 5198-5205.

31. Kayaki, N., Kawasaki, A., Ebata, T., Ohmoto, H., Ikeda, S., Inoue, S., Yoshino, K., Okumura, K., Yagita, H. (1995) Metalloproteinase-mediated release of human F as ligand. J. Exp. M ed. 182, 1777-1783.

32. Chen, A., Engel, P., Tedder, T. F. (1995) Structural requirements regulate endoproteolytic release of the $\mathrm{L}$-selectin $(C D 62 \mathrm{~L})$ adhesion receptor from the cell surface of leukocytes. J. Exp. Med. 182, 519-530.

33. Diaz-Gonzalez, F., Gonzalez-Alvaro, Y., Campanero, M. R., Mollinedo, F., del Pozo, M. A., Muñoz, C., Pivel, J. P., Sanchez-Madrid, F. (1995) Prevention of in vitro neutrophil attachment through shedding of $L$-selectin by non-steroidal antiinflammatory drugs. J. Clin. Invest. 95, 1756-1765.

34. del Pozo, M. A., Pulido, R., Muñoz, C., Alvarez, V., Humbría, A., Campanero, M. R., Sanchez-Madrid, F. (1994) Regulation of ICAM-3 (CD50) membrane expression on human neutrophils through a proteolytic shedding mechanism. Eur. J. Immunol. 24, 2586-2594.

35. Campanero, M. R., Pulido, R., Alonso, J. L., Pivel, J. P., Pimentel-Muiños, F. X., Fresno, M., Sanchez-Madrid, F. (1991) Downregulation by tumor necrosis factor- $\alpha$ of neutrophil cell surface expression of the sialophorin CD43 and the hyaluronate receptor CD44 through a proteolytic mechanism. Eur. J. Immunol. 21, 3045-3048.

36. Vu, T.-K., Hung, D. T., Wheaton, V. I., Coughlin, S. R. (1991) Molecular cloning of a functional thrombin receptor reveals a novel proteolytic mechanism of receptor activation. Cell 64, 1057-1068.

37. Vasalli, J. D., Sappino, A. P., Berlin, D. (1991) The plasminogen activator/plasmin system. J. Clin. Invest. 88, 1067-1072.

38. Smith, R. J., Speciale, S. C., Sam, L. M., Justen, J. M., Bowman, B. J. (1986) Requirement for cell bound proteases in the mechanism of human neutrophil activation with various stimuli. Inflammation 10, 257-270.

39. Kitakawa, S., Takafu, F., Sakamoto, S. (1980) Evidence that proteases are involved in superoxide production by human polymorphonuclear leukocytes and monocytes. J. Clin. Invest. 65, 74-81.

40. Keizer, G. D., B orst, J., Fidgor, C. G., Spits, H., Miedema, F., Terhorst, C., De Vries, J. E. (1985) Biochemical and functional characteristics of the human leukocyte membrane antigen family LFA 1, Mol. Eur. J. Immunol. 15, 1142-1148.

41. Barnstable, C. J., Bodmer, W. F., Brown, G., Galfre, G., Milstein, C., Williams, A. F., Ziegler, A. (1978) Production of monoclonal antibodies to group A erythrocytes, HLA and other human cell surface antigens: new tools for genetic analysis. Cell 14, 9-20.

42. Mollinedo, F., Nieto, J. M., Andreu, J. M. (1989) Cytoplasmic microtubules in human neutrophil degranulation: reversible inhibition by the colchicine analog 2-methoxy-5-(2'.3',4'-trimethoxyphenyl)-2,4,6-cycloheptatrien-1one. Mol. P harmacol. 36, 547-555.

43. Mollinedo, F., Burgaleta, C., Velasco, G., A rroyo, A. G., A cevedo, A., Barasoain, I. (1992) Enhancement of human neutrophil functions by a monoclonal antibody directed against a 19-kDa antigen. J . Immunol. 149, 323-330.

44. Lacal, P., Pulido, R., Sanchez-M adrid, F., Mollinedo, F. (1988) Intracellular localization of T200 and Mol glycoprotein in human neutrophils. J. Biol. Chem. 263, 9946-9951.

45. Mollinedo, F., Perez-Sala, D., Gajate, C., Jimenez, B., R odriguez, P., Lacal, J. C. (1993) Localization of rap1 and rap2 proteins in gelatinase-containing granules of human neutrophils. F EBS Lett. 326, 209-214.

46. Bellacosa, A., Lazo, P. A., Bear, S. E., Tsichlis, P. N. (1992) The rat leukocyte antigen MRC OX-44 is a member of a new family of cell surface glycoproteins which appears to be involved in growth regulation. Mol. Cell. Biol. 11, 2864-2872.

47. Kishimoto, T. K., Jutila, M. A., Berg, E. L., Butcher, E. C. (1989) Neutrophil Mac-1 and MEL-14 adhesion proteins are inversely regulated by chemotactic factors. Science 245, 1238-1241.

48. Torres, M., H all, F. L., O'N eill, K. (1993) Stimulation of human neutrophils with formyl-methionyl-leucyl-phenylalanine induces tyrosine phosphorylation and activation of two distinct mitogen-activated protein-kinases. J. Immunol. 150, 1563-1578. 
49. Dang, P. M., Rais, S., Hakim, J., Perianin, A. (1995) Redistribution of protein kinase $\mathrm{C}$ isoforms in human neutrophils stimulated by formyl peptides and phorbol myristate acetate. Biochem. Biophys. Res. Commun. 212, 664-672.

50. Nishizuka, Y. (1995) Protein kinases 5: protein kinase $C$ and lipid signalling for sustained cellular reponses. FASE B J. 9, 484- 496.

51. Matiana, J., Singhal, P. C. (1995) Macrophage Fc receptor activity modulates mesangial cell proliferation and matrix synthesis. Am. J. Physiol. 266, 568-575.

52. Angelisova, P., VIcek, C., Stefanova, I., Lipoldova, M., H orejsi, V. (1990) The human leucocyte surface antigen CD 53 is a protein structurally similar to the CD 37 and MR C OX 44 antigens. Immunogenet. 32, 281-285.

53. Tomlinson, M. G., Hanke, T., Hughes, D. A., Barclay, A. N., Scholl, E., Wright, M. D. (1995) Characterization of mouse CD53: epitope mapping, cellular distribution and induction by $T$ cell receptor engagement during repertoire selection. Eur. J. Immunol. 25, 2201-2206.
54. Hemler, M. E., Mannion, B. A., Berditchevski, F. (1996) Association of TM 4SF proteins with integrins: relevance to cancer. Biochem. Biophys. Acta 1287, 67-71.

55. Barcia, R., García-Vargas, S., Bosca, L., Lazo, P. A . (1996) CD53 antigen and epidermal growth factor induce similar changes in the pattern of phorbol ester binding in a B cell lymphoma. Cell. Immunol. 169, 107-112.

56. Olweus, J., L und-J ohansen, F., H orejsi, V. (1993) CD53, a protein with four membrane-spanning domains, mediates signal transduction in human monocytes and B cells. J. Immunol. 151, 707-716.

57. Rasmussen, A., Blomhoff, H. K., Stokke, T., H orejsi, V., Smeland, E. B. (1994) Cross-linking of CD53 promotes activation of resting human $B$ Iymphocytes. I. Immunol. 153, 4997-5007.

58. Mollinedo, F., Fontán, G., Barasoaín, I., Lazo, P. A. (1997) Recurrent infectious diseases in human CD53 deficiency. Clin. Diagnost. Lab. Immunol. 4, 229-231. 